\title{
The state of urban road infrastructure and the implementation of the FRSC speed limiting devices in Nigeria
}

\author{
J. J. Dukiya \\ Federal University of Technology, Minna, Nigeria
}

\begin{abstract}
Transportation is an essential part of human activity, and in many ways forms the basis of all socio-economic interactions. Since the first Ford's Model Ts vehicle in 1908 which has metamorphosed into the present day high speed hybrid vehicles, yearly auto-crash leads to the death of 1.2 million people, injury and disability of another 50 million is challenging. Speeding is one of the most common contributing factors of traffic crashes and in Nigeria, the overall road traffic injury rate is about 41 per 1000 population and mortality from road traffic injuries is about 1.6 per 1000 population. This paper examines the effectiveness of automated speed control devices implementation in Nigeria in the face of dearth of ITS infrastructure in the country. The reason for speeding problem of speeding and the state of road infrastructure in the country were also examined. The paper reveals that effective control through speed limiting devices are ITS infrastructure based and that African countries like Nigeria is ripe for full ITS adaptation. It is therefore recommended among other things that the implementing agency should re-prioritize their road safety strategies while encouraging the government to increase budgetary allocation to ITS infrastructural development nationwide.
\end{abstract}

Keywords: road infrastructure, ITS, speeding, road crash, traffic safety.

\section{Introduction}

Transportation is an essential part of human activity, and in many ways form the basis of all socio-economic interactions. Indeed, no two locations will interact effectively without a viable means of movement. In many developing countries, 
inadequate transport facilities are often the norm rather than the exception. Thus, a good transport system is essential to support economic growth and development. Science and technological advancement is not so pronounced in any sector globally as in the transportation sector. The automobile industry has metamorphoses from the wind first Ford's Model Ts vehicle in 1908 to the present day intelligent electric vehicles, and the automobile industries all over the world are expected to evolve more sophisticated fast moving vehicles in responses to the global village syndrome.

Speeding is one of the most common contributing factors of traffic crashes. Data extracted from the Fatality Analysis Reporting System (FARS) show that the driver-level attribute "driving too fast for conditions or in excess of posted speed limit" is the critical contributing factor in more than 99 percent of all speeding-related fatal crashes, as defined by the US National Highway Traffic Safety Administration. A marginal number of drivers were determined to be speeding through citations of speeding violations reported to FARS [1].

In 2002, World Health Organization and World Bank made available data that indicate that road traffic injuries were the $11^{\text {th }}$ leading cause of death worldwide and accounted for $2.1 \%$ of all deaths globally. Furthermore, these road traffic deaths accounted for $23 \%$ of all injury deaths worldwide. In another report [2], it is stated that $90 \%$ of road traffic deaths occurred in low income and middleincome countries, where 5098 million people or $80 \%$ of the world's population live. It is expected that road traffic injuries will become $8^{\text {th }}$ leading cause of death by year 2030 if nothing is done to reverse the trend.

In Nigeria, a total of 4,260 people were killed in accidents across the country in 2012, the deaths occurred in 6,269 road traffic crashes with an average of 11 people are said to have been killed daily in road accidents across the nation (4015 p/yr) [3]. The overall road traffic injury rate is about 41 per 1000 population and mortality from road traffic injuries is about 1.6 per 1000 population. This is significant when the fact that majority of these injuries and deaths can be prevented $[4,5]$. While a total of 20,752 people sustained various degrees of injuries from the crashes indicating an average of 56 people being injured in road accidents daily according to the official statistics from the Federal Road Safety Corps (FRSC), [6]. But in UK and Germany, it is reported that 1754 and 3657 people die in road accidents per year respectively.

The FRSC have in the past listed some of the major causes of road accidents nationwide to include over speeding, drunk driving, ignoring road signs and bad roads. Speeding is a critical factor in every serious crash, and speeding was identified as a contributing factor in an estimated $36 \%$ of fatal crashes between the year 2007 and 2011. Reductions in the average travel speed is the most effective and swift way to reduce road trauma and would produce significant and immediate road safety benefits.

The risk of a casualty crash approximately doubles with each $5 \mathrm{~km} / \mathrm{h}$ increase in speed on a $60 \mathrm{~km} / \mathrm{h}$ speed limited road, or with each $10 \mathrm{~km} / \mathrm{h}$ increase in speed on $110 \mathrm{~km} / \mathrm{h}$ roads. It is illegal to drive at any speed above the speed limit, see Figures 1 and 2 for the graphical representation of effects of increasing speed above approved speed limit per roadway [7]. 


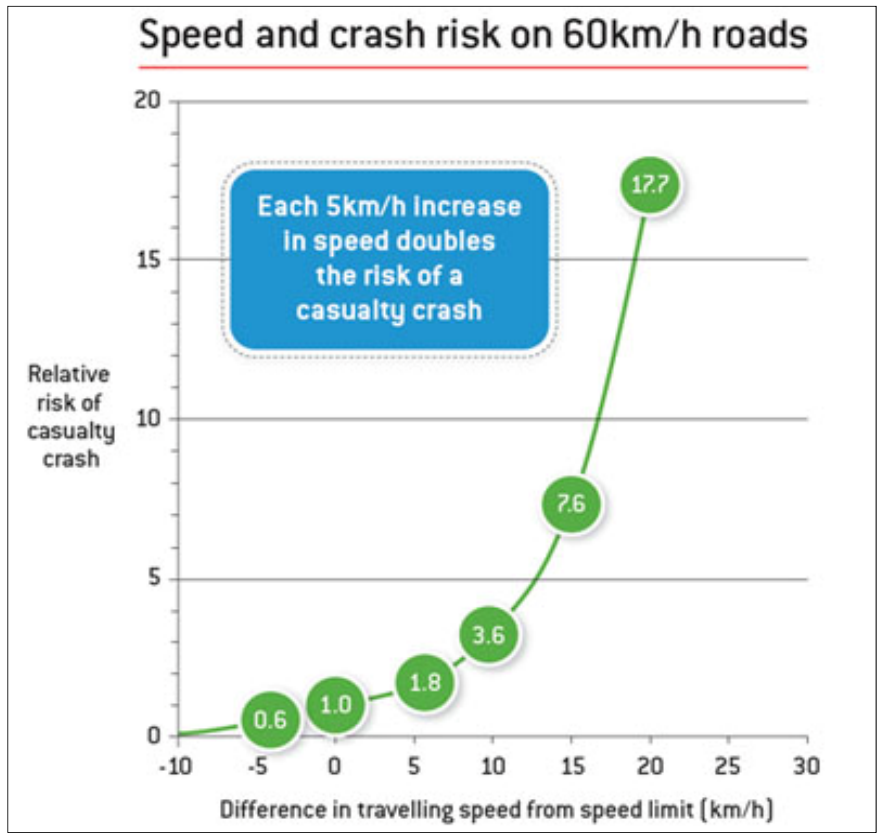

Figure 1: Risk of increasing driving speed above limits. Source: [7].

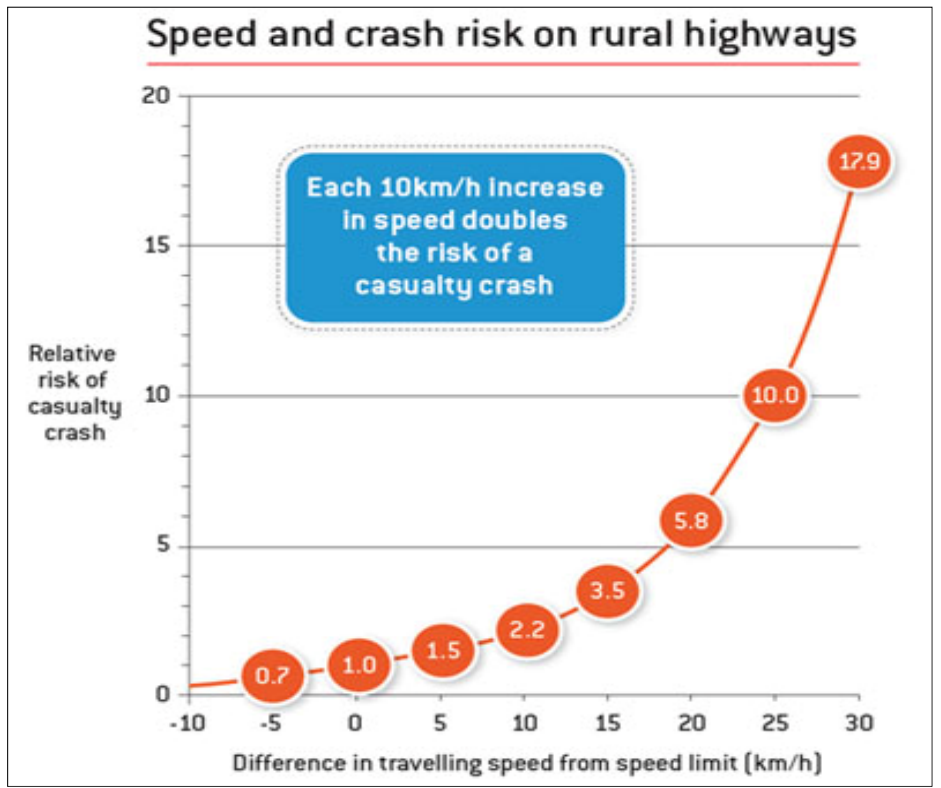

Figure 2: Risk of increasing driving speed above limits. Source: [7]. 
In South Australia for instance, a reduction of $5 \mathrm{~km} / \mathrm{h}$ in average travel speed reduce rural casualty crashes by about $30 \%$ and urban crashes by about $25 \%$. This is highly significant in lives and injuries saving for a nation.

\subsection{Aim and objectives of the study}

This paper is aimed at examining the effectiveness of automated speed control devices implementation in Nigeria in the face of dearth of ITS infrastructure in the country. This is to be achieved through the following objectives:

i. Examine the reasons and consequences of speeding in relation to automobile technological advancement.

ii. Examine the existing records on speed related road accidents and the ITS infrastructure development and management in the country.

iii. Assess the countries' FRSC operating infrastructure in relation to best practices in the world and recommend the way forward.

\section{Types of speed limit}

When discussing speeding, no matter how knowledgeable or experienced a driver is behind-the-wheel, history dictates that such cannot make the speeding vehicle defy physics. One will need at least $18.59 \mathrm{~m}$ and 1.07 seconds to stop a vehicle travelling at $15.53 \mathrm{~km} / \mathrm{ph}$, and a length of $106.68 \mathrm{~m}$ and 3.2 seconds are required to stop a vehicle travelling at $43.49 \mathrm{~km} / \mathrm{ph}$. A critical factor in the relationship between speed and crashes is the safe stopping distance that consists of: the distance travelled by the vehicle in which the driver to react to a scene; and the distance travelled to bring the vehicle to a stop.

There are two major types of speed limit which are:

i. Mandatory speed limit, and

ii. Reasonable speed limit.

The mandatory speed limit is the statutory definite speed limit imposed by the government of a nation for rural and urban roads above which an offence punishable by law has being committed. While the reasonable speed limit has no definite specified upper limit but each circumstance determine the speed limit for the road user. Research into the capacity of the human body to absorb crash energy indicates that speeds would ideally be less than $30 \mathrm{~km} / \mathrm{h}$ in where conflict with people walking and cycling is possible. As speed increases, a driver has less time to react to emergencies and requires a greater distance to stop.

\subsection{Reason for speeding}

There are multiple reasons for automobile users over speeding as examined by Morrris [8], but they are all within the following:
i. General attitude of being in a hurry
ii. Inattentive to driving condition (absent mindedness)
iii. Traffic laws are for some categories of people
iv. Not mindful of the danger inherent in dangerous driving behaviours 


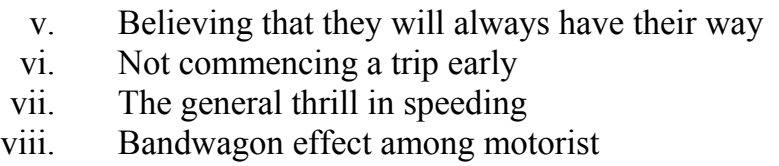

\subsection{The effects of over speeding}

i. Inability to read and observe traffic sign posts and less time to react to avoid a crash

ii. it takes longer time to stop the vehicle to avoid a crash

iii. Lost lives - over 4,260 each year (see Figure 3)

iv. Work zone crashes and fatalities - GDP

v. Unsafe school zones - compliance with lower speed limits is poor

vi. Economic costs - speed-related crashes cost society over $\$ 40$ billion annually

vii. Societal socio-cultural Trauma

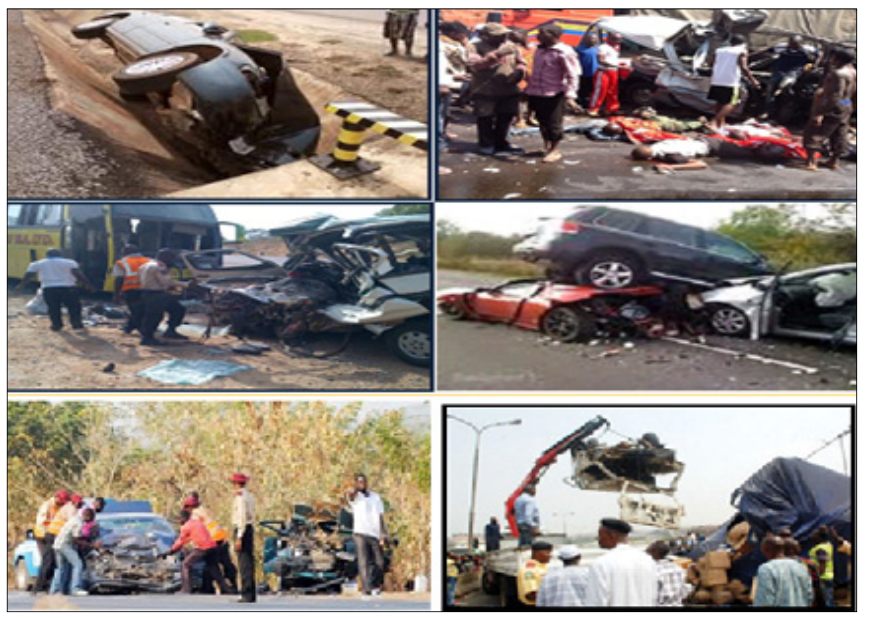

Figure 3: Rescue operation in action after road carnage along expressway.

Speeding is behavioural, although drivers acknowledge the fact that speeding is dangerous to their safety, yet still speeding. Commercial motorcyclist are the most vulnerable in uncontrolled speeding that usually resulted in various degrees of hazards [9]. Speed limits that are not set for the road environment and traffic conditions tend not to be respected by drivers and when lax enforcement is noticed by drivers, they reflect in their driving behaviour.

In Spain for instance, despite the existing laws, the number of injuries and deaths attributable to speeding and drunk driving is still extremely high. One year after the penalty points system was introduced, the main traffic offences punishable by penalty points were occurring at the following rates: speeding, $39.3 \%$; non-compliance with wearing passive restraint devices, $15.5 \%$; drunk 
driving, $11.6 \%$. To further reduce road injuries linked to these behaviours, the penal code was modified on 1 December 2007. Several traffic offences were criminalized which reduces road crashes significantly [10].

\section{Intelligent Transportation Systems (ITS)}

Intelligent Transportation Systems (ITS) refers to the application of communications and information technology to transport infrastructure and/or to vehicles to improve the efficiency of transportation networks [11]. In a typical ITS application, software is employed for traffic simulation, for real-time control and for communications. Transportation Systems projects may be broadly divided into infrastructure projects and vehicle-orientated applications; see Figure 4. Typical infrastructure projects include the installation of Dynamic Message Sign (DMS) along a freeway or the implementation of intelligent traffic light control for city streets. Vehicle-orientated projects include applications such as automated vehicle location and scheduling. Vehicular ITS applications are frequently applied to transit vehicles and corporate fleets [12].

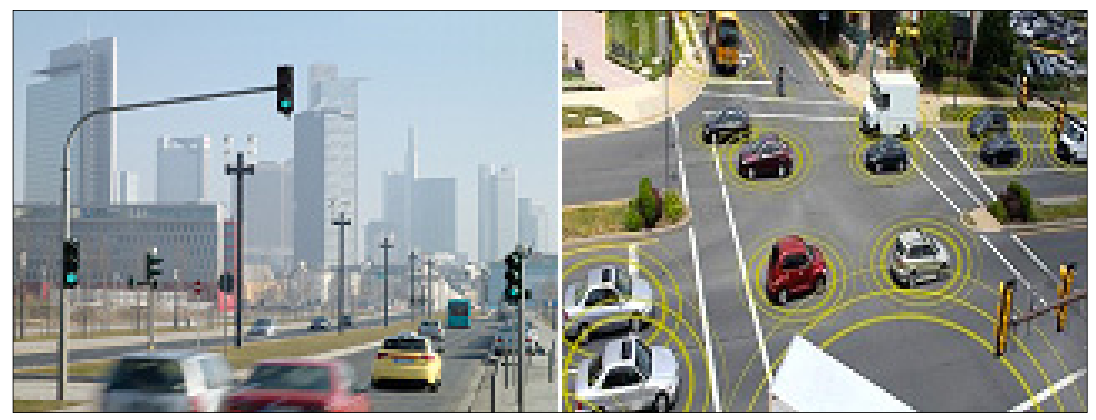

Figure 4: Road infrastructure and vehicle in-built ITS in operation.

ITS includes but is not limited to the following:

i. Surveillance and dispatch systems that improve incident response and clear problems sooner. Accidents and breakdowns are the source of 60 percent of traffic congestion.

ii. Electronic signs that strategically advise drivers of alternate routes, point to the nearest available parking, or display the exact time until "next bus" arrivals at transit stops.

iii. Fast, automatic, electronic fee collection at parking facilities, on toll bridges and freeways.

iv. Cable TV channels and Web sites that provide electronic maps showing bus location and video of freeway congestion areas.

Automated speed enforcement brings reductions in speed and crashes where it is implemented. Additionally, speeds and crashes tend to increase when automated speed enforcement programs are discontinued. This technology has an advantage of providing visible and ongoing enforcement with minimal disruption 
of traffic flow and devoid of observation, chase and citation, which can be hazardous and expensive and are not desirable for high-risk areas like work zones, see Figure 5. A traffic enforcement camera system for instance, consisting of a camera and a vehicle-monitoring device, is used to detect and identify vehicles disobeying a speed limit or some other road legal requirement and automatically ticket offenders based on the license plate number [13].

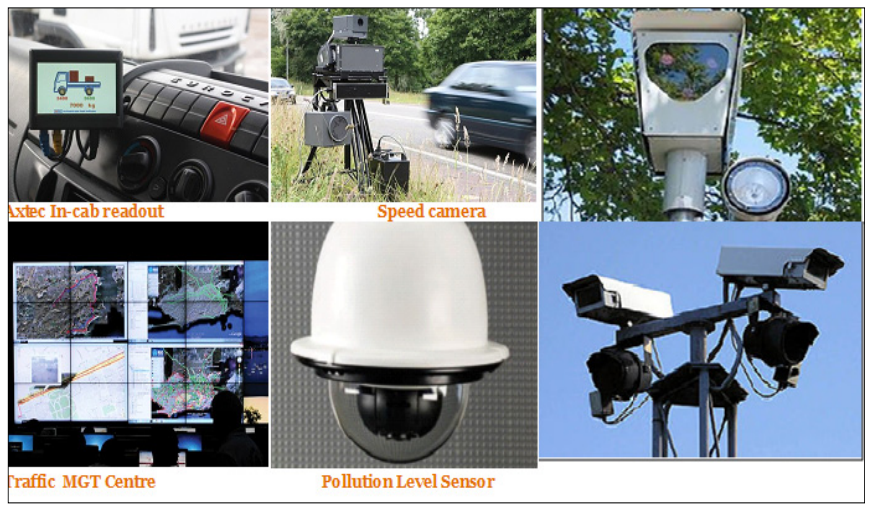

Figure 5: ITS Infrastructure in Operation.

\subsection{Intelligent Speed Adaptation (ISA)}

A proposal before the Mobility and Transport Department of the European Commission would require all new cars sold in the European Union to be fitted with speed limiting devices that would restrain vehicles from travelling at more than at $43.49 \mathrm{~km} / \mathrm{ph}$. The plan could outfit new cars with cameras that read posted speed limit signs on roadsides and relay the information to a computer, which would moderate excessive speed by applying a car's brakes without driver control.

According to Britain's Telegraph, "the scheme would work either using satellites, which would communicate limits to cars automatically, or using cameras to read road signs. Drivers can be given a warning of the speed limit, or their speed could be controlled automatically under the new measures". All cars could be fitted with devices that stop them going over at $70 \mathrm{~m} / \mathrm{ph}$, under new EU road safety measures which aim to cut deaths from road accidents by a third. The devices to be fitted to vehicles and motorcycle could be any of the following depending on nations ITS infrastructural facilities [14, 15], see Figure 6.

Intelligent Speed Adaptation (ISA) which is a positive research response to "driving too fast for conditions" (DTFFC) and "exceeding posted speed limit" (EPSL), is a vehicle inbuilt system that uses vehicle to infrastructure interface on the position of the vehicle in a network in relation to the speed limit in force at that particular location. It is very feasible in metropolitan areas that have attained the "smart city" status. Practical successful experiments with ISA have been carried out in Sweden with the open ISA (warning/informing) and the half- 
open ISA (the active accelerator) in four different town/cities and In the Dutch town of Tilburg with the closed ISA. Other field trials have taken place in Belgium, Denmark, Britain, Finland, Germany, France, Hungary and Spain. Actual experience with ISA seems to increase its acceptability by car drivers.

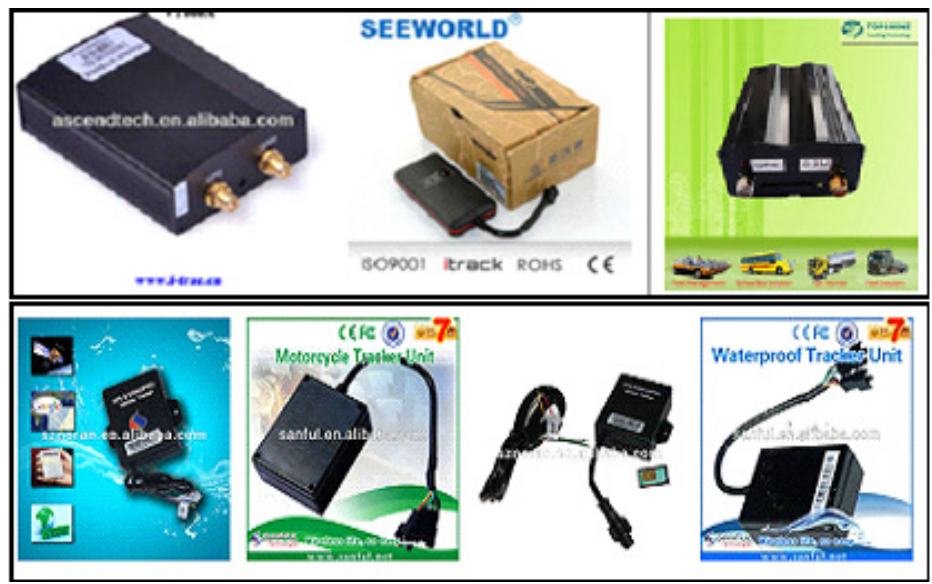

Figure 6: GPS vehicle and motorcycle speed control devices (US \$36-43 (\#6,520)/Piece).

\subsection{The Road infrastructural development in Nigeria}

Road infrastructural development in Nigeria is not poor comparatively since transportation system in the country is monoglot in nature as demonstrated in some cities like Abuja the capital city and Lagos. The Federal Capital City (FCC) is a purpose built city that made it exclusive for a social class, a situation that can be best be described as 'Abuja et le désert Nigériane si the répliqua of Paris et le désert français'; see Figure 7 for road development in FCC.

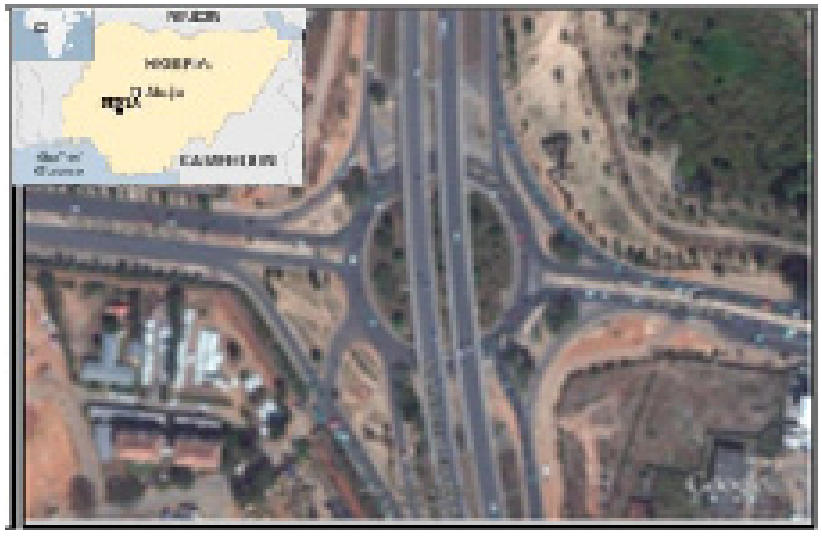

Figure 7: Road network in Abuja, Nigeria. Source. [16]. 
Lagos, the former capital city of the country is another urban centre in the country with standard road network comparable to any city in the world', but yet to be ITS compliace, see Figure 8 for such a road network.
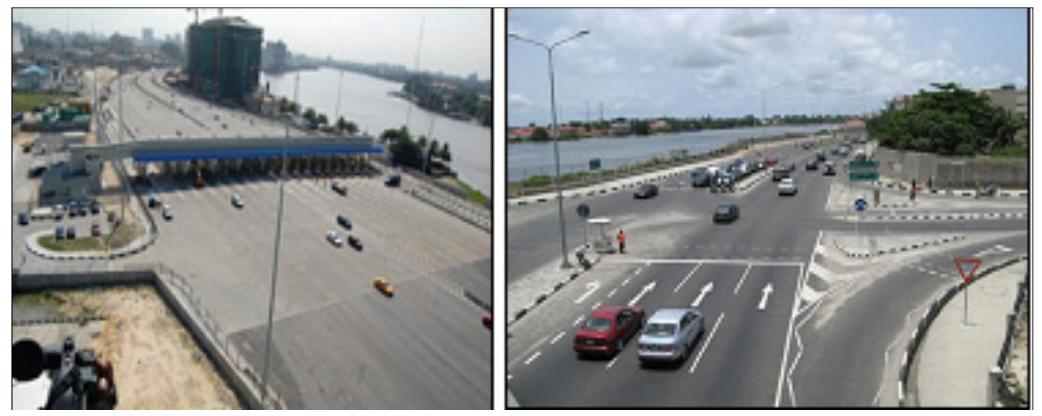

Figure 8: Road network in Victoria Island Lagos, Nigeria.

Generally in the other part of the country, there is a gap in the coordination of research and development in Nigeria transport industry with proliferation of management bodies [17]. Nigeria ranks 135th in term of infrastructure development in the world according to the World Economic Forum with urban dwellers spending a huge chunk of their productive time in traffic holdups costing the country billions of naira in time lost. Some roads are awarded for construction several times due to corruption while some are abandoned. Transport development is often short-term return focused on investments, which is a barrier to R and D and technology. The country has become a "now-now" and "sharp-sharp" society whose only concern is for the present under the democratic government.

\section{The challenge to the Nigerian government}

The major challenging issue in the country is that neither the FRSC nor the traffic unit of the police has the required ITS mobile infrastructure to commence the vehicle tracking as envisage in the new plate number. The road networks in the country are not yet equipped with the necessary ITS infrastructure. At best, the commission has only established their own patrol van tracking for rescue operations and surveillance. A comparative assessment of the Nigeria's FRSC patrol car and that of other countries like USA reveal the level of preparedness of the commission and the country at large, see Figure 9.

\section{Conclusion}

Transport management is an interdisciplinary activities that requires continuous research and development that is backed up with budgetary funding. The globalization of transportation standards and hybrid vehicles require the adoption 
of ITS infrastructural development that must be strategically planed and not by piece-meal approach as it is in developing countries like Nigeria.

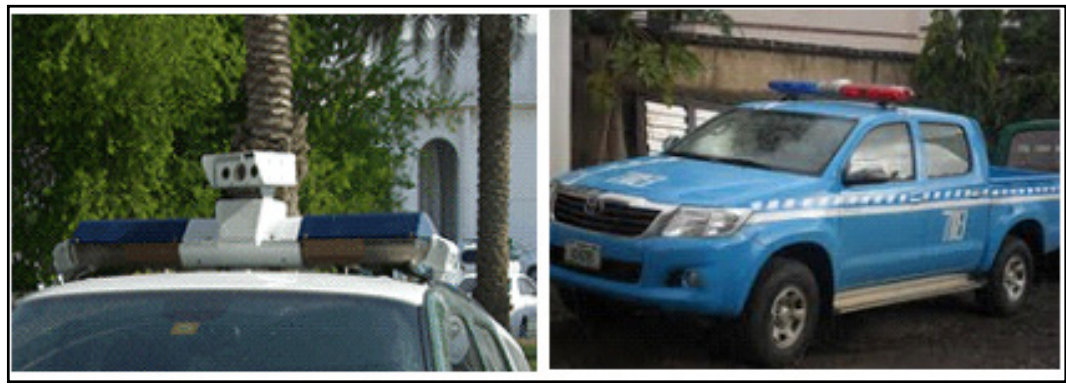

Figure 9: A mobile tracking system of the US Police and the FRSC patrol vehicle of Nigeria.

\subsection{The way forward}

i. All the major urban centres and highways in the country should be fully covered with current cadastral maps that are geo-reference for ITS adaptation. Development control should be more effective.

ii. The ministry of transport should collaborate with the nation's space agency for the full adaptation of the country's communication satellite to ITS utilization.

iii. The FRSC in conjunction with other relevant government agencies should convene a standing technical panel comprising individuals with backgrounds in the design, development, and safety assurance of automotive electronics systems that will handle ITS related issues.

iv. The speed control devices are just a subset of a set in the whole gamut of ITS adoption. A strategic long and short range plan ITS should be evolved and doggedly implemented for the country.

\section{References}

[1] Cejun Liu and Chou-Lin Chen. An Analysis of Speeding-Related Crashes:

[1] Definitions and the Effects of Road Environments. In Technical Report of National Highway Traffic Safety Administration 14, 2009. New Jersey Avenue SE. Washington, DC 20590, the National Technical Information Service, Springfield, Virginia 22161.

[2] World Urbanization Prospects: The 2003 Revision (Population, www.ebookscentral.com/book/65410/world-urbanization.

[3] Oluwasanmi A. J. (1993). Road traffic accident trends in Nigeria. Accident Analysis \& Prevention; 25(4): 485-487.

[4] Eze Bun. Road Traffic Accidents in Nigeria: A Public Health Problem. In AFRIMEDIC Journal Volume 3, No. 2, pp. 35-36, 2012. 
[5] Ezenwa A. O. Trends and characteristics of road traffic accidents in Nigeria. Perspective in Public Health; 106(1): pp. 27-29. 1986.

[6] FRSC, FRSC-and-new-number-plate, 2011. http://www.businessday online.com/NG/index.php/analysis/commentary/.

[7] Kloeden C. N., McLean A.J., Moore V.M., Ponte G. 'Travelling Speed and the Risk of Crash Involvement', Volume 1 - Findings. NHMRC Road Accident Research Unit, The University of Adelaide, November 1997. casr.adelaide.edu.au/speed/vol-1.html.

[8] Morris, E. Top Causes of Car Accidents. 2006, September 18. http://ezinearticles.com/?Top-Causes-of-Car-Accidents\&id=302163.

Retrieved June. 11, 2012.

[9] Adeyemo, A.M., An appraisal of motorcycle as a commercial passenger mode in Port Harcourt Metropolis. Journal of Transport Studies, Vol. 2, No. 1, pp. 76, 1998.

[10] Ana M Novoa, Katherine Pérez, Elena Santamariña-Rubio \& Carme Borrell 'Effect on road traffic injuries of criminalizing road traffic offences: a time-series study'. Bulletin of the World Health Organization 2011; 89: 422-431. doi: 10.2471/BLT.10.082180.

[11] John N. Technology \& transportation: The dynamic relationship. Discovery Institute, Vol. X No. II. 2001. www.discovery.org.

[12] USDOT. ITS Strategic Research Plan, 2010-2014. http://www.its.dot.gov/ strat_plan/index.htm Retrieved June, 2012.

[13] "Q\&As: Red light cameras". Insurance Institute for Highway Safety. December 2010. http://www.iihs.org/research/qanda/rlr.html. Retrieved 16 December 2010.

[14] Devices to limit car speed in new plan from EU/Herald Scotland. www.heraldscotland.com/news/transport/devices-to-limit.

[15] UK fights EU bid to introduce speed limit devices World. www.theguardian.com/.../01/UK-fights-EU-speed-limit-devices.

[16] Google Earth Extract, 2012.

[17] Ogunsanya A. A., Analysis of Nigerian Government Policy on Urban Transportation. Pub. by Nigerian Institute of Transport Technology (INTT), Zaria, pp. 2003-223, 2004. 